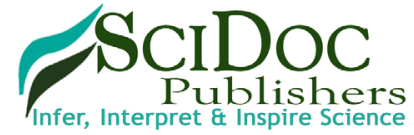

\section{Influence of Mental Health on Preventive Behavior towards Premature - Sexual Intercourse among Junior High School Students in Thailand}

Research Article

Pramote Wongsawat $^{1 *}$, Sitthisak Tikham ${ }^{1}$, Saychit Suknoo ${ }^{1}$, Supaporn Sudnongbua ${ }^{1}$

${ }^{1}$ Faculty of Public Health, Naresuan University, Phitsanulok, Thailand.

\title{
Abstract
}

This study aimed to identify influence of mental health on preventive behavior towards premature-sexual intercourse among junior high school students in Thailand. A cross-sectional survey, consisting of a questionnaire was self-administered to 260 junior high school students randomly selected by stratified sampling technique. Stepwise multiple regression analysis was performed to determine the factors included mental health affecting preventive behavior towards sexual intercourse among junior high school students. Seven factors were statistically significant with preventive behavior towards sexual intercourse among junior high school students and were found to make a unique contribution to this prediction. Correlation for regression was significantly different with $\mathrm{R}^{2}$ at 0.422 . The adjusted $\mathrm{R}^{2}$ value of 0.407 indicated that $40.7 \%$ of the variability in mental health affected on preventive behavior towards sexual intercourse among junior high school students. The seven factors were normal level of mental health $($ Beta $=0.482)$, sex values $($ Beta $=0.431)$, knowledge of sex education $($ Beta $=$ 0.247) which associated positively towards preventive behavior in premature-sexual intercourse, junior high school students, who had alcohol drinking, had less preventive behavior towards premature-sexual intercourse than those who had not (Beta $=-0.159)$, junior high school students, who had money saving, had less preventive behavior towards premature-sexual intercourse than those who had not (Beta $=-0.153$ ), being taught about sex education by parents affected negatively to preventive behavior towards premature-sexual intercourse among the students (Beta $=.142$ ), and the students, who had boy or girl friend, had less preventive behavior towards premature-sexual intercourse than those who had not (Beta $=-0.112)$. With respect to recommendations, junior high school students should be promoted mental health in order to increase preventive behavior towards premature-sexual intercourse.

Keywords: Mental Health; Preventive Behavior; Premature-Sexual Intercourse; Junior High School Students.

\section{Introduction}

Premature sexual intercourse or sexual intercourse among students has become a major issue in Thailand, as it affected to students' quality of life such as teen age pregnancy, sexually transmitted infection, education failure, and stigma in society. Aekplakorn, et al., studied sexual behavior among teens aged 10-19 and found that $17.9 \%$ of male students had had sexual intercourse and $7.3 \%$ of female students had had sexual intercourse [1]. According to pregnancy survey in Thailand in $2017,5.9 \%$ of female teens aged 10-17 had pregnancy [2]. Most pregnant teens have to cease their study in order to provide child care for their babies and also, they have to face with lack of income [3]. Department of Disease Control, Ministry of Public Health in Thailand reported that morbidity rate of sexually transmitted infection among teens aged 15-24 had increased from 19.03 in 2007 to 23.76 in 2015 [4]. In 2017, 129 teen students had sexually transmitted infection [5]. These situations illustrate that these effects cause from premature-sexual intercourse. Therefore, prevention of risk behavior towards premature-sexual intercourse in teens should be operated before they have sexual intercourse, or become early teens. The early teens should be evaluated pre-sexual behavior in order to prevent teenage pregnancy and sexually transmitted infection.

\section{Materials and Methods}

\section{Study Design}

A cross-sectional survey was employed among junior high school

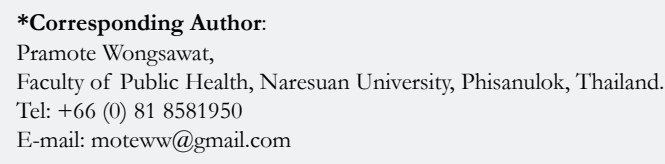

Citation: Pramote Wongsawat, Sitthisak Tikham, Saychit Suknoo, Supaporn Sudnongbua. Influence of Mental Health on Preventive Behavior towards Premature - Sexual Intercourse among Junior High School Students in Thailand. Int J Chronic Dis Ther. 2019;5(1):82-86. doi: http://dx.doi.org/10.19070/2572-7613-1900016

Copyright: Wongsawat $\mathbf{P}^{\circ}$ 2019. This is an open-access article distributed under the terms of the Creative Commons Attribution License, which permits unrestricted use, distribution and reproduction in any medium, provided the original author and source are credited. 
students who lived in muang district, Kamphaeng Phet province, Thailand where teenage pregnancy rate was reported in a highest level in Thailand [2]. Of those, 260 were selected randomly by stratified sampling technique and a questionnaire was selfadministered by those participants. A questionnaire consisted of close-ended questions emphasized on socio-demography, sexual risk behavior, sex education, attitude towards sex, being taught about sex education by teachers, being taught about sex education by parents, preventive behavior towards premature sexual intercourse, and mental health test from Ministry of Public Health. The Cronbach alpha coefficient in each part of the questionnaire was $0.71,0.86,0.82,0.78,0.79,0.75$, and 0.84 respectively.

\section{Subjects}

The subjects used for this study were drawn from all those aged between 14 and $16(\mathrm{~N}=3,242)$ registered at the selected randomly schools. Two-hundred-and-sixty student names were randomly selected as potential subjects in this study.

\section{Data Analysis}

Regarding the cross-sectional survey, its data were analyzed using SPSS. Descriptive statistics were used for summarizing sociodemography, sexual risk behavior, sex education, attitude towards sex. Stepwise multiple regression analyses were used to identify socio-demography, sexual risk behavior, sex education, attitude towards sex, being taught about sex education by teachers, being taught about sex education by parents, and preventive behavior towards premature-sexual intercourse affecting on normal level of mental health.

\section{Ethical Considerations}

Human Ethic procedures were approved by Naresuan University's Human Ethics Committee and carried out in accordance with the tenets of the Treaty of Helsinki. Potential subjects were contacted by the researcher and invited to participate in the study. The purposes of the study were explained to them. Also, they were informed that they had their rights to decline to participate, to withdraw from participation at any time or to refuse to answer any questions. The anonymity of the participants was protected with data stored by participant code only and kept in a controlled place. All data were damaged by document shredder and all electronic files were deleted.

\section{Results}

Regarding sample characteristics as well as socio-demography shown in Table 1 , the majority of respondents were female $(\mathrm{N}=$ 134; $51.5 \%$ ). Most of the subjects studied at junior high school level $3(\mathrm{~N}=95 ; 36.5 \%)$. Of overall subjects, over half of them had sufficient expenses $(\mathrm{N}=143 ; 55.0 \%)$. Most students reported that their parents' marital status was married ( $N=153 ; 58.8 \%)$, their fathers' occupation $(\mathrm{N}=125 ; 48.0 \%)$ and mother's occupation $(\mathrm{N}=138 ; 53.1 \%$ ) were employee. Most students were living with single father, single mother, or both parents $(\mathrm{N}=171 ; 65.8 \%)$. The major subjects lived in urban area $(\mathrm{N}=177 ; 68.1 \%)$. Most of them had normal level of metal health (mental health test from Ministry of Public Health) $(\mathrm{N}=187 ; 71.9 \%)$.

Table 1. Characteristics and socio-demography $(N=260)$.

\begin{tabular}{|c|c|}
\hline Characteristics and socio-demography & $\%($ number $)$ \\
\hline \multicolumn{2}{|l|}{ Gender } \\
\hline Male & $48.5(126)$ \\
\hline Female & $51.5(134)$ \\
\hline \multicolumn{2}{|l|}{ High school level } \\
\hline level 1 & $30.8(80)$ \\
\hline level 2 & $32.7(85)$ \\
\hline level 3 & $36.5(95)$ \\
\hline \multicolumn{2}{|l|}{ Sufficiency of expenses } \\
\hline not sufficient & $11.1(29)$ \\
\hline sufficient & $55.0(143)$ \\
\hline Sufficient and saving remain & $33.9(88)$ \\
\hline \multicolumn{2}{|l|}{ Marital status of parents } \\
\hline married & $58.8(153)$ \\
\hline Widowed/separated & $41.2(107)$ \\
\hline \multicolumn{2}{|l|}{ Father's occupation } \\
\hline employee & $48.0(125)$ \\
\hline farmer & $23.8(62)$ \\
\hline merchant & $15.4(40)$ \\
\hline government official & $2.3(6)$ \\
\hline other(unemployed, dead) & $6.5(17)$ \\
\hline \multicolumn{2}{|l|}{ Mother's occupation } \\
\hline employee & $53.1(138)$ \\
\hline farmer & $19.6(51)$ \\
\hline
\end{tabular}




\begin{tabular}{|c|c|}
\hline merchant & $19.2(50)$ \\
\hline government official & $1.9(5)$ \\
\hline other(unemployed, dead) & $6.2(16)$ \\
\hline People whom students are living with & $65.8(171)$ \\
\hline $\begin{array}{c}\text { living with single father/ single mother/ } \\
\text { both parents }\end{array}$ & $34.2(89)$ \\
\hline living with others & $68.1(177)$ \\
\hline Living area & $31.9(83)$ \\
\hline urban & $71.9(187)$ \\
\hline Suburb/rural area & $28.1(73)$ \\
\hline Mental health level & \\
\hline normal level & \\
\hline lower than normal level & \\
\hline
\end{tabular}

Table 2. Risk behaviors towards sexual intercourse $(N=260)$.

\begin{tabular}{|c|c|c|c|}
\hline \multirow{2}{*}{ Risk behaviors towards sexual intercourse } & \multicolumn{3}{|c|}{$\%($ number $)$} \\
\hline & male & female & Total \\
\hline \multicolumn{4}{|l|}{ Having had boyfriend/girlfriend } \\
\hline Yes & $61.1(77)$ & $79.9(107)$ & $70.8(184)$ \\
\hline No & $38.9(49)$ & $20.1(27)$ & $29.2(76)$ \\
\hline \multicolumn{4}{|l|}{ Having boyfriend/girlfriend } \\
\hline Yes & $28.6(39)$ & $53.4(70)$ & $41.9(109)$ \\
\hline No & $71.4(90)$ & $46.6(61)$ & $58.1(151)$ \\
\hline \multicolumn{4}{|l|}{ Having had alcohol drinking } \\
\hline No & $62.7(79)$ & $56.0(75)$ & $59.2(154)$ \\
\hline Yes & $37.3(47)$ & $44.0(59)$ & $40.8(106)$ \\
\hline rarely & $18.3(23)$ & $24.6(33)$ & $21.5(56)$ \\
\hline occasionally & $17.4(22)$ & $15.7(21)$ & $16.5(43)$ \\
\hline often & $1.6(2)$ & $3.7(5)$ & $2.8(7)$ \\
\hline \multicolumn{4}{|l|}{ Watching obscene book/porno book } \\
\hline No & $59.5(75)$ & $82.0(110)$ & $71.1(185)$ \\
\hline Yes & $40.5(51)$ & $18.0(124)$ & $28.9(75)$ \\
\hline once a month & $18.2(22)$ & $12.8(17)$ & $15.0(39)$ \\
\hline once a week & $12.0(15)$ & $3.8(5)$ & $7.7(20)$ \\
\hline every other day & $6.3(8)$ & $0.7(1)$ & $3.5(9)$ \\
\hline everyday & $4.8(6)$ & $0.7(1)$ & $2.7(7)$ \\
\hline \multicolumn{4}{|l|}{ Watching nude VDO or porn VDO } \\
\hline No & $46.8(59)$ & $78.3(105)$ & $63.1(164)$ \\
\hline Yes & $43.2(67)$ & $21.7(129)$ & $36.9(96)$ \\
\hline once a month & $38.1(48)$ & $18.7(25)$ & $28.1(73)$ \\
\hline once a week & $9.5(12)$ & $3.0(4)$ & $6.1(16)$ \\
\hline every other day & $2.4(3)$ & $0.0(0)$ & $1.2(3)$ \\
\hline everyday & $3.2(4)$ & $0.0(0)$ & $1.5(4)$ \\
\hline \multicolumn{4}{|l|}{ Having nightlife } \\
\hline No & $78.6(99)$ & $79.1(106)$ & $78.8(205)$ \\
\hline Yes & $21.4(27)$ & $20.9(128)$ & $21.2(55)$ \\
\hline rarely & $15.9(20)$ & $17.9(24)$ & $17.0(44)$ \\
\hline often & $5.6(7)$ & $3.0(4)$ & $4.2(11)$ \\
\hline
\end{tabular}

As can be seen in Table 2, risk behaviors towards sexual intercourse were divided into 6 major risk behaviors such as having had boy friend/girl friend, having boy friend/girl friend,having had alcohol drinking, watching obscene book/porno book, watching nude VDO or porn VDO, and having nightlife. $70.8 \%$ of total subjects had had boy friend/girl friend. Female students reported that $79.9 \%$ of them used to have boy friend. In contrast, only $61.1 \%$ of male students had had girl friend. In terms of having boy friend/girl friend in present, overall students reported that $41.9 \%$ of them had boy friend/girl friend. Over half of female 
Table 3. Factors affecting preventive behavior towards premature-sexual intercourse among junior high school students.

\begin{tabular}{|c|c|c|c|c|c|c|}
\hline Factors & B & R Square & R Square change & Beta & t-value & p-value \\
\hline Normal level of mental health & 4.428 & 0.250 & 0.000 & 0.482 & 7.988 & 0.000 \\
\hline Sex values & 0.717 & 0.262 & 0.012 & 0.431 & 7.667 & 0.000 \\
\hline Knowledge of sex education & 0.831 & 0.317 & 0.055 & 0.247 & 4.512 & 0.000 \\
\hline Alcohol drinking & -3.813 & 0.357 & 0.040 & -0.159 & 2.969 & 0.000 \\
\hline Money expenses and saving & -3.900 & 0.386 & 0.029 & -0.153 & 2.972 & 0.003 \\
\hline Being taught by parents & -0.309 & 0.406 & 0.020 & -0.142 & 2.158 & 0.012 \\
\hline Having boyfriend/girlfriend & -2.680 & 0.422 & 0.016 & -0.112 & 2.150 & 0.033 \\
\hline
\end{tabular}

Constant $=26.832$, Multiple $\mathrm{R}=0.650, \mathrm{R}$ Square $=0.422, \mathrm{R}$ Square Adjusted $=0.407$

students had boy friend $(\mathrm{N}=70 ; 53.4 \%)$, whereas $28.6 \%$ of male students had girl friend. With respect to alcohol drinking, over half of total subjects $(\mathrm{N}=154 ; 59.2 \%)$ did not have alcohol drinking. Male students did not have alcohol drinking $(\mathrm{N}=79$; $62.7 \%$ ) rather than female students $(\mathrm{N}=75 ; 56.0 \%)$. For watching obscene book/porno book and nude VDO, $71.1 \%$ of overall students had never watched obscene book/porno book and $63.1 \%$ of them had never watched nude VDO. $78.8 \%$ of overall students had never had nightlife.

As can be seen in Table 3, stepwise multiple regression was used to assess the ability of 10 control measures (having nightlife, watching nude VDO, watching obscene book/porno book, normal level of mental health, sex values, knowledge of sex education, alcohol drinking, money expenses and saving, being taught by parents, having boyfriend/girlfriend)to predict preventive behavior towards premature-sexual intercourse among junior high school students. Preliminary analyses were conducted to ensure no violation of the assumptions of normality, linearity, multicollinearity, and homoscedasticity [6]. The results were found that only seven control measures explained an additional $42.2 \%$ (40.7\% adjusted) of the variance. Seven control measures were statistically significant, with preventive behavior towards premature-sexual intercourse among junior high school students. Thus, these seven variables were found to make a unique contribution to this prediction. These variables were normal level of mental health $(\beta=0.482, \mathrm{p}<0.001)$, sex values $(\beta=0.431$, $\mathrm{p}<0.001)$, knowledge of sex education $(\beta=0.247, \mathrm{p}<0.001)$, alcohol drinking $(\beta=-0.159, \mathrm{p}<0.001)$, money expenses and saving $(\beta=-0.153, p=0.003)$, being taught by parents $(\beta=-0.142$, $\mathrm{p}=0.012)$, having boy friend $/$ girl friend $(\beta=-0.112, \mathrm{p}=0.033)$ respectively.

\section{Discussion}

The discussion integrates the findings to address the research objective. The factors influenced on preventive behavior towards premature-sexual intercourse among junior high school students were normal level of mental health, sex values, knowledge of sex education, alcohol drinking, money expenses and saving, being taught by parents, having boyfriend/girlfriend respectively.

Regarding normal level of mental health, students who had normal level of mental health would be able to have preventive behavior towards premature-sexual intercourse compared to the student who had not. Also, Svensson, F., Fredlund, C., Svedin, C., Priebe, G., and Wadsby, M. found that mental health associated with sex behavior in adolescents [7].
Sex value affects positively to preventive behavior towards premature-sexual intercourse because the right value of sex can cause appropriate sex behavior such as mature-sexual behavior [8]. Similarly, Rawajai found that sex value affected to risk behavior of sexual intercourse among students at collages in Bangkok [9]. This finding associated with Sawangtook and Thano's study [10]. They found that teen students who had different sex value would have different sex behavior. For example, teen students, who reserved themselves from premature-sexual intercourse, would have preventive behavior.

Knowledge of sex education affected positively to preventive behavior towards premature-sexual intercourse because education could lead to good practice [11]. Thus, sex education can cause prevention of premature-sexual intercourse among junior high school students. Besides, Danpradit, et al., [12] found that sex education program affected significantly to avoidance of premature-sexual intercourse and teenage pregnancy. Having knowledge of sex education can lead to low risks of prematuresexual intercourse among teens [13].

In terms of alcohol drinking, students, who have alcohol drinking, will have less preventive behavior of premature-sexual intercourse than those who have not. Alcohol will make people lose self-control and it can lead to have sexual intercourse easily [14]. Likely Lekphet, et al., [15] found that high school students who had alcohol drinking had higher risks of sexual intercourse than those who had not.

Students who have sufficient expenses and money saving will have less preventive behavior of premature-sexual intercourse than those who have not because student who have much money will be able to spend money for sexual intercourse at nightclub. Teen students are not mature for money expenses, so that those expenses may lead to sexual intercourse without difficulty [16].

Being taught by parents can affect negatively to preventive behavior of premature-sexual intercourse. Too much parents' teachings to adolescents can lead to negative actions towards parents from those teens. Sahay, et al., [17] found that being taught frequently about safe sex or prevention of prematuresexual intercourse can cause risk behavior of premature-sexual intercourse because teenagers may feel bored or resist what parent teach [18]. Furthermore, Chaysree, et al., [19], Sidze \& Defo [20] found that family relationship associated with risk behavior towards premature-sexual intercourse. Also, weakness of family relationship can cause premature-sexual intercourse $[20,21]$. 
Students who have boyfriend or girlfriend trend to have less preventive behavior of premature-sexual intercourse than those who have not. Companionship, touching, and immaturity can cause premature-sexual intercourse [10]. In addition, Junnual, et al., [16] found that most early teens had first sexual intercourse with their boyfriend or girlfriend. Similarly, Wong-arsa, Kongnguen \& Vuthiarpa [22] found that having boyfriend among female teens associated with risk behavior towards prematuresexual intercourse.

\section{Conclusion}

To sum up, the findings of the study illustrated that factors included mental health affecting preventive behavior towards prematuresexual intercourse among junior high school students. The factors influenced on preventive behavior towards premature-sexual intercourse among junior high school students were normal level of mental health, sex values, knowledge of sex education, alcohol drinking, money expenses and saving, being taught by parents, having boyfriend/girlfriend respectively. These findings presented that mental health was the key factor for encouraging junior high school students to prevent premature-sexual intercourse.

\section{Acknowledgements}

I acknowledge the junior high school students in muang district, Kamphaeng Phet province, Thailand for sharing their experiences. Also, I kindly thank school directors in muang district, Kamphaeng Phet province for providing me some useful information and the convenience to access to the research area. In terms of the research grant, I have to thank the National Research Council of Thailand (NRCT) for providing me financial support.

\section{References}

[1]. Aekplakorn W, Puckcharern H, Thaikla K, Atheannoppakao W. Thai National Health Examination Survey. Health System Research Institute: Nonthaburi, Thailand; 2016

[2]. Bureau of Reproductive Health, Department of Health, Ministry of Public Health (2017) Situation of Reproductive Health among adolescents and youth in 2017, cited 2019 March 18.

[3]. Nithitantiwat P, Pataipakaipet K. Unwanted pregnancy and abortion: Preventive guidelines for adolescents. J Boromarajonani Coll Nurs, Bangkok. 2016;32(2):133-9.

[4]. Department of Disease Control, Ministry of Public Health. Guideline of Surveillance for Action system: 5 Disease 5 Aspect, Annual of 2016. TS Printing: Nonthaburi, Thailand; 2016.

[5]. Kamphaengphet Provincial Health Office. Analysis of Epidemiological Situ- ation. 2017. Available from: https://mis2.kpo.go.th/epidem.

[6]. Pallant J. SPSS survival manual: A step by step guide to data analysis using IBM SPSS. 5th ed. Open University Press: New York; 2013.

[7]. Svensson F, Fredlund C, Svedin CG, Priebe G, Wadsby M. Adolescents selling sex: Exposure to abuse, mental health, self-harm behaviour and the need for help and support-a study of a Swedish national sample. Nord J Psychiatry. 2013 Apr;67(2):81-8. doi: 10.3109/08039488.2012.679968. PubMed PMID: 22563767.

[8]. Office of the National Culture Commission, Ministry of Culture. Value and environments of Thai society in youth's perspectives. Kurusapa Printing Ladphrao: Bangkok, Thailand; 2006.

[9]. Rawajai, N. Factors influencing sexual risk preventive behaviors of students in vocational education commission Bangkok metropolistan. Master's thesis Srinakharinwirot University: Bangkok, Thailand; 2011.

[10]. Sawangtook S, Thano P. The study of the awareness of sexual risk behaviors and sexual risk behaviors of adolescent students. Kuakarun J Nur. 2015;22(2):41-56.

[11]. Pirantaowad O. Communication for motivation. 4th ed. Chulalongkorn University Press: Bangkok, Thailand; 2006.

[12]. Danpradit P, Karuhadej P, Yingpaiboonsuk U, Kittichottipanich B, Suaysom P. Effects of Applying Self-Efficacy Theory and Life Skills Enhancement Program on Sexual Relation Avoidance Confidence and Pregnancy Prevention among Sexually At-Risk Teenage Female Students. J Nur Sci Chulalongkorn Univ. 2018:30(1):11-22.

[13]. Kaewviengdach C, Hirunwatthanakul P. Factors Associated with Sexual Risk Behaviours Among Secondary School Students in Nakhon Phanom Province. J Royal Thai Army Nurs. 2016;17(3):168-177.

[14]. Coleman LM, Cater SM. A qualitative study of the relationship between alcohol consumption and risky sex in adolescents. Arch Sex Behav. 2005 Dec;34(6):649-61. PubMed PMID: 16362249.

[15]. Lekphet K, Wongsawat P, Tejativaddhana P, Michaeng S. Effecting factors of sexual relationship experiences among upper secondary school students. Res Dev Health Sys J. 2015;8(1):163-174.

[16]. Junnual N, Manwong M, Suebsamran P, Singto S. Factors Related to Sexual Behavior among the Lower Secondary School Students at a school in Ubon Ratchathani Province. The Public Health Journal of Burapha University 2014;9(2):56-65.

[17]. Sahay S, Nirmalkar A, Sane S, Verma A, Reddy S, Mehendale S. Correlates of sex initiation among school going adolescents in Pune, India. Indian J Pediatr. 2013 Oct;80(10):814-20. doi: 10.1007/s12098-013-1025-8. PubMed PMID: 23604612

[18]. Isaranurug S, Suthisukon P. Child care and Teaching. Journal of Public Health and Development. 2007;5(1):105-118

[19]. Lassana Chaisri, Chareonporn Suphapai, Piyathida Khajornchaikun, Pratana Satitwipawee. Factors influencing sexual risk behavior of high school students in Prachuap Khiri Khan Province. Journal of Public Health. 2010; 40 (2): 161-74.

[20]. Sidze EM, Defo BK. Influences of family structure experiences on the risk of premarital sexual initiation during adolescence in Cameroon. Adv Life Course Res. 2013 Dec;18(4):270-87. doi: 10.1016/j.alcr.2013.09.002. PubMed PMID: 24796711.

[21]. Pupunhong W, Wuttisin K, Traitip T. Factors Related to Sexual Behavior of Teenagers in Amphoe Meuang Kalasin Province. Prae-wa kalasin journal of Kalasin University. 2016;3(2): 54-71.

[22]. Wong-Arsa W, Kongnguen P, Vuthiarpa S. Factors affecting sexual risk behaviors among adolescents: a Case Study Conducted in One University. Journal of Public Health. 2015;45(3):285-97. 